\title{
Special Anesthesiologic Considerations in Robot-Assisted Thoracic Surgery
}

\author{
Christoph Niklas ${ }^{1} \cdot$ Bastian Fakundiny ${ }^{2} \cdot$ Anton Popov $^{2} \cdot$ Thorsten Walles $^{2}$
}

Accepted: 10 June 2021 / Published online: 28 July 2021

(C) The Author(s) 2021

\begin{abstract}
Purpose of Review This review summarizes the key issues for preoperative, peri- and intraoperative, and postoperative patient management for robotic-assisted thoracic surgery (RATS). It provides practical guidance for anesthesiologists and thoracic surgeons starting a RATS program.

Recent Findings RATS is a new technological approach to execute minimal invasive chest operations. In management of RATS patients, the established ERAS principles for video-assisted thoracoscopic surgery (VATS) apply. In addition, RATS imposes additional conditions on anesthesiologists, nurses, and surgeons alike: The spatial constriction in operation theaters caused by the large robotic equipment longs for a reallocation of the anesthetist's and surgeon's working environment that may vary additionally depending on the type of surgery performed in the individual patient. Additionally, the implementation of a positive pressure carbon dioxide gas cavity in the pleura has a direct effect on patient cardio-circulatory and respiratory mechanics that have to be balanced by the anesthesiologist. Summary RATS advances by replacing open surgery approaches and will complement—but most likely not replace-videoassisted thoracoscopic surgery (VATS). RATS brings new specific intraoperative requirements to the anesthesiological and surgical team members that have to be implemented into clinical routine.
\end{abstract}

Keywords Anesthesiology - Arrangement of resources - Intraoperative considerations · Operation room utilization · Robotic-assisted thoracoscopic surgery

\section{Introduction}

Minimal invasive surgical approaches by video-assisted thoracoscopic surgery (VATS) have been established in clinical

This article is part of the Topical Collection on Thoracic Anesthesia

Thorsten Walles

thorsten.walles@med.ovgu.de

Christoph Niklas

christoph.niklas@med.ovgu.de

Bastian Fakundiny

bastian.fakundiny@med.ovgu.de

Anton Popov

anton.popov@med.ovgu.de

1 University Clinic for Anesthesiology and Intensive Therapy, Magdeburg University Medicine, Leipziger Straße 44,

39120 Magdeburg, Germany

2 Department of Thoracic Surgery, Magdeburg University Medicine, Leipziger Straße 44, 39120 Magdeburg, Germany practice for the surgical treatment of diseases of the lung, esophagus, and mediastinum [1-3]. Patients benefit from a reduction in the surgical trauma translating into reduced postoperative stress response. Ultimately, postoperative pulmonary complication rates and length of stay decrease and patient satisfaction increase [4*0]. Thoracic surgery clinics worldwide make use of these positive effects and combine them with optimized pre- and postoperative anesthesiologic and conservative management to generate comprehensive enhanced recovery programs for their patients to optimize clinical performance and patient satisfaction and to minimize hospital and especially intensive care resource requirements $[5 \bullet \bullet, 6]$.

In the last decade, robotic-assisted thoracoscopic surgery (RATS) has emerged as a new treatment modality for thoracic surgery patients [7-10] (Fig. 1). The RATS approach is attractive for surgeons since it facilitates complex minimal invasive surgical preparations in delicate and confined anatomical regions. Numerous studies have documented safety as well as oncological equivalence of RATS compared to open surgery and VATS approaches [11-13]. As a result, RATS applications for 


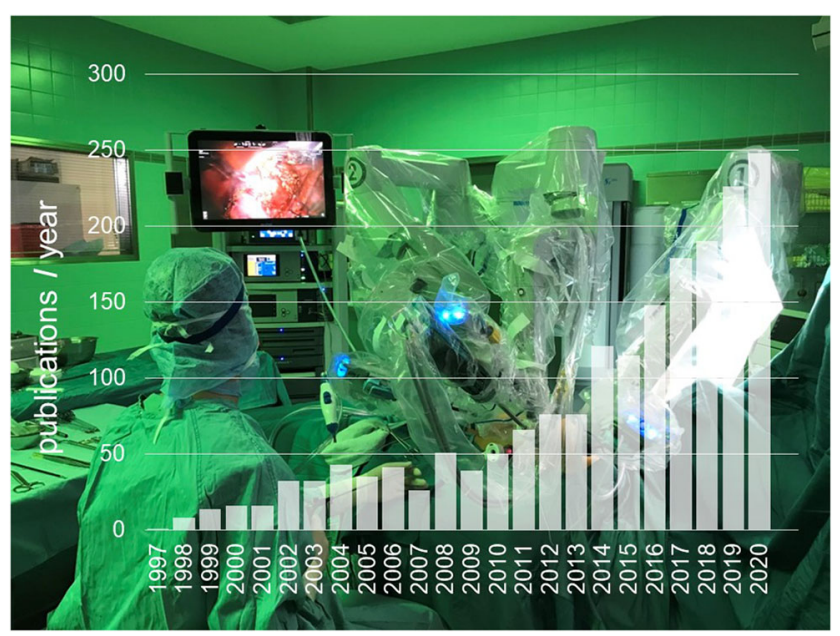

Fig. 1. Timeline of publications on "robot-assisted thoracic surgery." A Medline research documents a rapid development of this field since the first publication in 1997.

anatomical lung resections including lymphadenectomy, esophageal resections, and resection of mediastinal tumors are continuously increasing [14]. Currently, RATS has to step up to document its added value compared to considerably increased treatment costs $[15,16 \cdot 17]$. As robotic surgical platforms continue to evolve, this dilemma will eventually be overcome.

For the surgeon, the advantages of RATS include true 3dimensional imaging with binocular glasses and the use of multiarticular forceps that allow the performance of highprecision operations [18]. For both the surgeon and the anesthesiologist, there is a multitude of perioperative considerations for RATS surgery [19]. This article focuses upon preoperative patient optimization, intraoperative considerations for surgeons and anesthesiologists, and postoperative management of patients undergoing RATS surgery.

\section{Preoperative Considerations}

Premedication and Preoperative Assessment RATS of the chest affects-similar to VATS approaches-not only the respiratory but also the cardiovascular system. Preoperative patient evaluation for RATS therefore parallels that for VATS [20]. It is crucial to assess patients carefully regarding preexisting cardiovascular or respiratory disease in order to detect any issues that might jeopardize the outcome and to ensure the optimal anesthetic regime [20]. Electrocariography is performed for cardiac evaluation. If signs of cardiac malperfusion are detected, further examinations like cardiac ultrasound or coronary angiography are needed [21-22]. Furthermore assessment of right ventricular function can be useful [23]. Pulmonary evaluation should include a chest Xray and any computed tomography testing needed for surgical assessment and planning. Any signs of emphysema, pulmonary obstruction, or infection must be taken into consideration when assessing the pulmonary reserve. Lung function tests are required before thoracic surgery [24]. Here, $\mathrm{pCO}_{2}, \mathrm{FEV}_{1}$, and diffusion capacity for carbomonoxide are the main parameters that must be considered. As far as capillary blood gases are concerned, the partial pressure of carbon dioxide $\left(p \mathrm{CO}_{2}\right)$ and for oxygen $\left(p \mathrm{O}_{2}\right)$ are of interest as they reflect the preoperative ventilatory state of the patient. The $\mathrm{pH}$ highlights whether the patient is acidotic or alkalotic. Acidosis can be due to the retention of $\mathrm{CO}_{2}$ or the accumulation of acidotic metabolites, whereas alkalosis can be caused by hyperventilation or renal diseases. Other laboratory findings of interest are the inflammatory state of the patient, pictured by C-reactive protein, interleukins, and leukocytes, as well as the metabolic situation including blood glucose and triglycerides along with the thyroid status [25-27]. As in any other preoperative evaluation, hints towards a difficult management of the airway must be noted (Mallampati score, previous anesthetic management, thyro-mental gap, deviation or compression of the trachea seen in X-rays) [28-30]. Thoracic CT imaging done in diagnostics and planning of the surgery is also useful for the anesthetist [27]. If the patient shows extraordinary high anxiety, a sedating premedication with benzodiazepines is administered as long as there are no contraindications [31]. Finally, the different modalities for postoperative pain control should be discussed with the patient to identify a suitable strategy for the individual patient and prepare the required interventions, if needed (e.g., epidural catheter or patient-controlled intravenous analgesia) [6]. In most RATS interventions, multimodal analgesics combined with local anesthesia of the surgical incisions are considered sufficient for pain control $[32,22]$. Intercostal nerve blockade and submuscular analgesic depositories may be applied additionally [33, 34]. Especially patients with an increased surgical likelihood for conversion to thoracotomy should be counselled very differentiated.

\section{Preoperative Rehabilitation and Medical Optimization} Preexisting comorbidities should be controlled, and modifiable risk factors and medications should be optimized before surgery $[24,33]$. To minimize postoperative pulmonary complications and impaired wound healing, smoking cessation should be encouraged as far in advance as possible [5••, 33]. Previous studies have shown that the risk for these complications including death is inversely correlated with the length of smoking cessation [35•]. The medication of patients with symptomatic chronic obstructive pulmonary disease should be optimized to minimize symptoms and the risk of intraand postoperative deterioration. Exercise prehabilitation has been suggested to improve patients' preoperative health status 
and to reduce postoperative complications. However, a recent meta-analysis was not able to show relevant effects on postoperative complication rates in lung cancer patients [36].

\section{Peri- and Intraoperative Considerations}

Limited Patient Accessibility Patient positioning in VATS and RATS operations is similar. However, to facilitate RATS interventions, the robotic device has to be positioned directly next to the operation table and connected to the patient. The current large and cantilevered systems inevitably block patient accessibility for surgeon and anesthesiologist, requiring a re-arrangement of equipment (e.g., anesthesia workstation, perfusors) and staff (Fig. 2) [37]. Depending on the spatial conditions in the individual surgical theaters, this may limit anesthesiological accessibility of the head, airways, and upper torso. Extensions for intravenous lines, the arterial line, and the airway circuit may be necessary [19]. It is mandatory that the anesthesiology staff ensure that these vital connections are visible and accessible. In the course of surgery, manipulations of these lines will be very difficult with the robotic system connected to the patient.

Perioperative Antibiotic Therapy No difference has been shown regarding surgical site infections (SSI) for RATS and open thoracic surgery [38]. Currently there are no consented guidelines for surgical antibiotic prophylaxis neither before VATS nor RATS surgery. The ERAS/ESTS guideline for lung surgery recommends the use of preoperative prophylactic antibiotics in order to decrease the rate of SSI [5*0]. However, there was no effect on the postoperative pneumonia or empyema rate. Our hospital policy is to administer a first generation Cephalosporine (e.g., Cefuroxim) intravenously no more than 60 min prior to skin incision, usually at the time of anesthesia induction. Our rationale is that Cephalosporines cover the bacteria identified in the skin and respiratory flora and that the drugs share both low-cost and low allergic potential [39].

Airway Management In general, RATS procedures are performed under single-lung ventilation. For airway separation, double-lumen tubes or bronchial blocking devices are applied $[40,41]$. In studies no advantages of either device have been shown [42-44]. The decision how to instrument the airways depends on (1) patient-specific factors (e.g., difficult airway), (2) local hospital standards, and (3) practical experience of the individual anesthesiologist. When choosing a double-lumen tube, the left bronchial version is preferred whenever possible to reduce the risk of tube dislocation by accidental movement. The correct placement of the lung separation device must be controlled after initial placement and must be reevaluated after the patient is positioned by the surgeon.

Patient Positioning Mediastinal tumors are resected either from the right or the left chest cavity with the patient

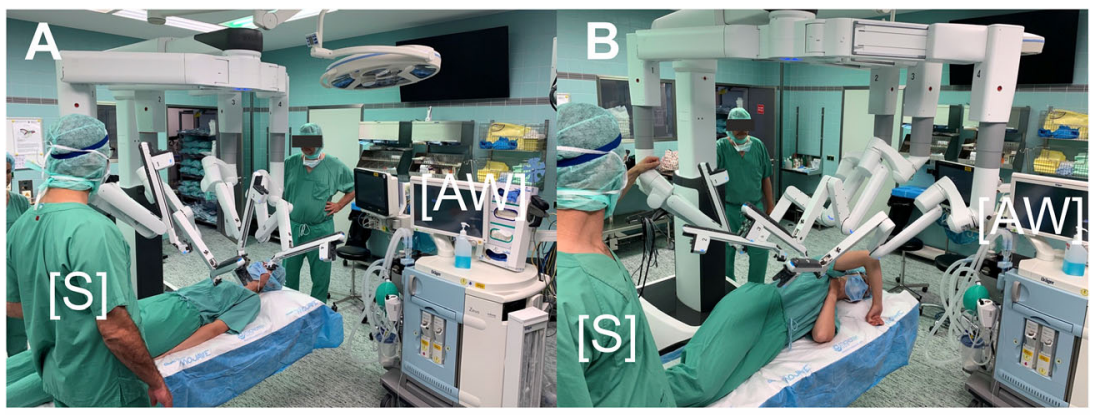

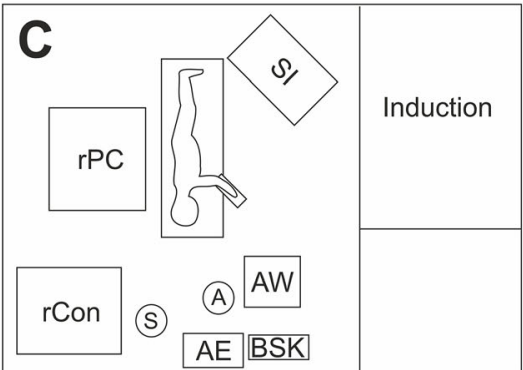

Fig. 2. Spatial constraints in robotic-assisted thoracic surgery require modifications in operation room utilization. The spatial arrangement of anesthesiologic equipment and resources may vary according to the particular surgical procedure. A RATS intervention for the mediastinum. The patient is positioned on its back, and the surgical instruments may be inserted either from the left or right pleural cavity.

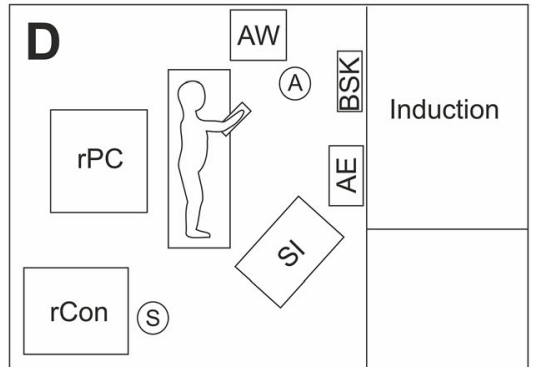

B RATS intervention of the lung. The patient is positioned on its opposite side to grant access to the target organ. C, D Arrangement of the anesthesiologic and surgical equipment for interventions $\mathbf{C}$ on the left lung and $\mathbf{D}$ on the right lung (AW, anesthesia workstation; S, surgeon; A anesthetist; BSK, bronchoscopy equipment; AE, anesthesia equipment; rCon, robotic console; rPC, robotic patient cart; SI, surgical instruments). 
positioned on the back. For pulmonary RATS procedures, patients are placed in lateral decubitus position [7-10]. Operation tables may be curved up to $30^{\circ}$ to enlarge the intercostal space. To avoid injuries of the cervical spine, the head must be rested carefully. The anesthesiologist must be aware that airway devices are likely to dislocate during these surgical positioning maneuvers. Even small unintended changes may impair single-lung ventilation significantly. To ensure proper airway instrumentation for RATS surgery, bronchoscopy is mandatory after patient positioning is finalized. Only now the bronchial cuff of the double-lumen tube, respectively the balloon of the bronchial blocker, is inflated under bronchoscopic control [40, 41].

Patient Ventilation To maximize the available intrapleural space, $\mathrm{CO}_{2}$ is insufflated to the upper hemithorax during RATS. This results in increased ventilation pressure, higher $\mathrm{pCO}_{2}$ with acidosis and hemodynamic compromising by pressure-induced compression of the mediastinal vessels $\rightarrow$ Video). To avoid ventilation trauma, a protective lung ventilation with a VT of 5-6 ml/kgIBW (ideal body weight) and a pressure limit of $30 \mathrm{cmH}_{2} \mathrm{O}$ should be applied. Hypercapnia can be tolerated to a $\mathrm{pH}$ of 7.25. Patients should be extubated at the end of surgery.

Patient Monitoring Beside routine monitoring (ECG, pulse oximetry, etCO $\mathrm{CO}_{2}$, temperature), the use of an arterial line is mandatory for continuous measurement of the arterial blood pressure and regular blood gas analysis. The usefulness of central venous pressure monitoring in lateral position is discussed controversially. The placement of a central line should be decided upon the patient's cardiac condition and the status of the peripheral veins. It should be kept in mind that it is nearly impossible to place a central line while the patient is positioned for the surgical procedure.

Anesthesia Maintenance General anesthesia with endotracheal intubation is suggested by the requirements for profound immobility and controlled ventilation with lung isolation with capno-pneumothorax. Anesthesia can be conducted either as total intravenous or as volatile anesthesia. The latter have shown to decrease inflammation after one-lung ventilation. To reduce postoperative pulmonary complications, the use of short-acting opioids is recommended in the phase of maintenance.

Vascular Access Adequate large-bore venous access should be in place to perform resuscitation in the event of significant bleeding. At least two peripheral intravenous lines are inserted into the vena basilica or cephalica and securely fixed to prevent dislocation. A central venous line is not usually established unless the patient is likely to need high doses of vasopressors. As one-lung ventilation is required for surgery which leads to alterations in gas exchange, an arterial catheter is inserted in the radial artery to regularly take blood gas samples and to measure the blood pressure.

Hemorrhagic Complications Injury to the hilar pulmonary and mediastinal vessels and to the aorta may cause fatal hemorrhagic complications. Numerous studies have shown that lifethreatening hemorrhagic complications may occur in a small group of patients undergoing RATS surgery $[45 \bullet \cdot, 46]$. Most bleedings can be controlled short term by manual compression of the surgical assistant using a swab. For surgical vascular repair, undocking of the robotic device and a thoracotomy are mandatory. The surgical team including anesthesia and nursing teams should be prepared to complete this process swiftly. Therefore, all instruments for thoracotomy should be available in the operation room [19].

Preventing Hypothermia Perioperative hypothermia increases SSI rates, the need for blood transfusions, and cardiac morbidity and mortality. It should therefore be avoided by any means [47]. To optimize patient treatment, numerous patient- and anesthesia-specific factors have to be addressed: (1) patient age, (2) BMI, (3) comorbidities, and (4) length of the operation. Patient temperature management should ideally begin with prewarming before commencing anesthesia: The patient should also be actively warmed if the length of the operation is expected to exceed $60 \mathrm{~min}$ (> $30 \mathrm{~min}$ without prewarming) [48]. Intraoperative temperature management includes conductive/convective warming techniques, thermal insulation of the greatest possible body surface area, and warming of infusions and transfusions, given at a rate greater than $500 \mathrm{ml} / \mathrm{h}[49]$.

\section{Postoperative Considerations}

Pain Management Postoperative pain management should include regional and intravenous components as well. A combination of NSAID and long-acting opioids at the end of surgery and regional anesthetic techniques has shown good results in our patient collective. Every patient gets local anesthetic (i.e., ropivacaine) by the surgeon at the surgical incisions. Providing analgesia in the complete chest wall can be accomplished by performing fascial plane blocks, preferably a serratus anterior plane block. While epidural analgesia is a good option in open thoracic surgery, the cost-benefit balance is not appropriate in RATS procedures.

Antithrombotic Treatment Thoracic surgery patients in general are at a high risk of deep venous thrombosis and postoperative thromboembolism. Therefore, the European ERA/ESTS and ESA guidelines for thoracic surgery suggest the use of mechanical and pharmaceutical thrombembolism prophylaxis [5••, 50]. 
In contrast, the German AWMF guideline does not comment on mechanical thrombosis prophylaxis but recommends pharmaceutical thrombosis prophylaxis in all cancer patients [49]. It exempts younger non-cancer patients that undergo minor RATS procedures (e.g., diagnostic thoracoscopy, pleurectomy) from pharmaceutical thrombembolism prophylaxis. However, all procedures that involve lung resection, mediastinal procedures, or pleural empyema should be treated as medium or major thoracic surgery, and pharmaceutical prophylaxis is recommended. Our hospital policy is the use of low-molecular-weight heparin (e.g., tinzaparin) administered once daily until full patient mobility is restored. Recent studies have discussed the use of extended pharmacological prophylaxis up to 1 month after surgery [52, 53]. However, the level of recommendation for thoracic surgery is weak. Extended pharmacological prophylaxis after RATS should therefore be limited to selected patients with increased risk for venous thromboembolism [51].

Respiratory Physiotherapy Early patient mobilization is considered important to reduce postoperative pulmonary complications [5••, 6]. However, evidence for efficiency of postoperative patient mobilization is small [54, 55]. Ideally, standard mobilization is conducted by the nursing staff on postoperative day (POD) one. The need for physiotherapy is defined individually. Considerations for low thresholds towards physiotherapy are 1) performed surgical procedure, 2) presence of chronic obstructive pulmonary disease, 3) preoperative mobility, 4) body mass index and 5) age [56,57•]. In our clinic practice, we apply routine incentive spirometry in all patients undergoing RATS even though benefit is lacking evidence [58, 59]. But incentive spirometry has been shown to motivate patients to perform regular breathing exercises by themselves and picks them up to be part of the convalescence.

Chest Tube Removal Timely chest tube removal has been shown to be a critical component of early recovery after thoracic surgery $[5 \bullet \bullet, 6]$. However, there are no specific recommendations for RATS. Whereas suggestions for an evidencebased approach to manage the pleural space have been made, clinical practice still varies largely according to surgeon preference and institutional tradition [60-62*0]. According to current recommendations, chest tube can be safely removed in the absence of any air leak. Electronic drainage systems are able to quantify air leak and intrathoracic pressures and therefore provide objective standards for chest tube removal $[5 \bullet \bullet, 6,61,63]$. Regarding pleural fluid output, a threshold of up to $300 \mathrm{ml} / 24 \mathrm{~h}$ of non-chylous, non-hematic fluid has been shown to be efficient $[62,64]$. In this context, the use of the pleura/bloodprotein ratio has been suggested to be helpful to determine the transition of pleural effusions from the exudative to the transudative phase [65].

\section{Conclusion}

Robotic-assisted thoracoscopic surgery (RATS) is becoming increasingly prevalent in thoracic surgery programs. As a new technological approach RATS enables minimal invasive chest operations and helps to replace thoracotomies. For patient management, the well-elaborated interdisciplinary recommendations for early recovery after surgery are applied. Anesthesiologists are part of every RATS treatment team and have to be familiar with those considerations to safeguard optimal treatment results. Moreover, RATS impacts the intraoperative working environment of anesthesiologists significantly and simultaneously has direct effects on patients' cardio-circulatory and respiratory function.

Abbreviations $A$, Anesthetist; $A E$, Anesthesia equipment; $A W M F$, Association of the Scientific Medical Societies in Germany; $A W$, Anesthesia workstation; BMI, Body mass index; $B S K$, Bronchoscopy; $B W$, Body weight; $\mathrm{CO}_{2}$, Carbon dioxide; $E C G$, Electrocardiography; $E R A S$, Enhanced recovery after surgery; ESA, European Society of Anesthesiology; ESTS, European Society of Thoracic Surgeons; et $\mathrm{CO}_{2}$, End tidal $\mathrm{CO}_{2} ; F E V_{l}$, Forced expiratory ventilation volume; $\mathrm{min}$, Minute; $N S A I D$, Non-steroidal anti-inflammatory drug; $p \mathrm{CO}_{2}$, Partial pressure of carbon dioxide; $\mathrm{pO}_{2}$, Partial pressure of oxygen; $P O D$, Postoperative day; RATS, Robotic-assisted thoracoscopic surgery; $r$ Con, Robotic console (=component of robotic surgery system); $r P C$, Robotic patient cart (=component of robotic surgery system); S, Surgeon; SI, Surgical instruments; SSI, Surgical site infection; VATS, Video-assisted thoracoscopic surgery; $V T$, Tidal volume

Supplementary Information The online version contains supplementary material available at https://doi.org/10.1007/s40140-021-00471-4.

Code Availability Not applicable.

Author Contribution Christoph Niklas and Thorsten Walles contributed to the articles conception and design. Data collection and analysis was performed by all authors. The manuscript draft was written by Christoph Niklas and Thorsten Walles, and all authors commented on previous versions of the manuscript. All authors read and approved the final manuscript and agree to be accountable for all aspects of the work in ensuring that questions related to the accuracy or integrity of any part of the work are appropriately investigated and resolved.

Funding Open Access funding enabled and organized by Projekt DEAL.

Data Availability Not applicable.

\section{Compliance with Ethical Standards}

Ethics Approval Not applicable.

Consent to Participate Not applicable.

Consent for Publication Not applicable. 
Conflict of Interest The authors have no relevant financial or nonfinancial interests to disclose.

Human and Animal Rights and Informed Consent This article does not contain any studies with human or animal subjects performed by any of the authors.

Open Access This article is licensed under a Creative Commons Attribution 4.0 International License, which permits use, sharing, adaptation, distribution and reproduction in any medium or format, as long as you give appropriate credit to the original author(s) and the source, provide a link to the Creative Commons licence, and indicate if changes were made. The images or other third party material in this article are included in the article's Creative Commons licence, unless indicated otherwise in a credit line to the material. If material is not included in the article's Creative Commons licence and your intended use is not permitted by statutory regulation or exceeds the permitted use, you will need to obtain permission directly from the copyright holder. To view a copy of this licence, visit http://creativecommons.org/licenses/by/4.0/.

\section{References}

Papers of particular interest, published recently, have been highlighted as:

- Of importance

•. Of major importance

1. Berfield KS, Farjah F, Mulligan MS. Video-assisted thoracoscopic lobectomy for lung cancer. Ann Thorac Surg. 2019;107:603-9.

2. Xie A, Tjahjono R, Phan K, Yan TD. Video-assisted thoracoscopic surgery versus open thymectomy for thymoma: a systematic review. Ann Cardiothorac Surg. 2015;4:495-508.

3. Booka E, Takeuchi H, Kikuchi H, Hiramatsu Y, Kamiya K, Kawakubo H, et al. Recent advances in thoracoscopic esophagectomy for esophageal cancer. Asian J Endosc Surg. 2019;12:19-29.

4.・ Elsayed HH, Moharram AA. Tailored anaesthesia for thoracoscopic surgery promoting enhanced recovery: the state of the art. Anaesth Crit Care Pain Med. 2021;40:100846. https://doi. org/10.1016/j.accpm.2021.100846 very important article Anesthesiologic perspective on early recovery after thoracic surgery. This review focuses on the key anaesthetic elements during the preoperative, intraoperative and postoperative period.

5.• TJP B, Rasburn NJ, Abdelnour-Berchtold E, Brunelli A, Cerfolio RJ, Gonzalez M, et al. Guidelines for enhanced recovery after lung surgery: recommendations of the Enhanced Recovery After Surgery (ERASVR) Society and the European Society of Thoracic Surgeons (ESTS). Eur J Cardiothorac Surg. 2019;55: 91-115 Surgical perspective on early recovery after thoracic surgery. This systematic review presents consensus recommendations for the optimal preadmission, admission, intraoperative and postoperative management of patients undergoing thoracic surgery. Key recommendations include preoperative counselling, nutritional screening, smoking cessation, prehabilitation for high-risk patients, avoidance of fasting, carbohydrate loading, avoidance of preoperative sedatives, venous thromboembolism prophylaxis, prevention of hypothermia, short-acting anaesthetics to facilitate early emergence, regional anaesthesia, nausea and vomiting control, opioid-sparing analgesia, euvolemic fluid management, minimally invasive surgery, early chest drain removal, avoidance of urinary catheters and early mobilization after surgery.

6. Berna P, Quesnel C, Assouad J, Bagan P, Etienne H, Fourdrain A, et al. Guidelines on enhanced recovery after pulmonary lobectomy. Anaesth Crit Care Pain Med. 2021;40:100791. https://doi.org/10. 1016/j.accpm.2020.100791.

7. Melfi FM, Fanucchi O, Davini F, Mussi A. VATS-based approach for robotic lobectomy. Thorac Surg Clin. 2014;24:143-9.

8. Marulli G, Rea F, Melfi F, Schmid TA, Ismail M, Fanucchi O, et al. Robot-aided thoracoscopic thymectomy for early-stage thymoma: a multicenter European study. J Thorac Cardiovasc Surg. 2012;144: 1125-30.

9. van Boxel GI, Kingma BF, Voskens FJ, Ruurda JP, van Hillegersberg R. Robotic-assisted minimally invasive esophagectomy: past, present and future. J Thorac Dis. 2020;12:54-62.

10. Schwartz G, Sancheti M, Blasberg J. Robotic Thoracic Surgery. Surg Clin North Am. 2020;100:237-48.

11. Yang HX, Woo KM, Sima CS, Bains MS, Adusumilli PS, Huang J, et al. Long-term survival based on the surgical approach to lobectomy for clinical stage I nonsmall cell lung cancer: comparison of robotic, video-assisted thoracic surgery, and thoracotomy lobectomy. Ann Surg. 2017;265:431-7.

12. Marulli G, Comacchio GM, Stocca F, Zampieri D, Romanello P, Calabrese F, et al. Robotic-assisted thymectomy: current perspectives. Robot Surg. 2016;3:53-63.

13. van der Sluis PC, van der Horst S, May AM, Schippers C, Brosens LAA, Joore HCA, et al. Robot-assisted minimally invasive thoracolaparoscopic esophagectomy versus open transthoracic esophagectomy for resectable esophageal cancer: a randomized controlled trial. Ann Surg. 2019;269:621-30.

14. Möller T, Egberts JH. Robot-assisted thoracic surgery-areas of application and limitations. Chirurg. 2021;92:122-7.

15. Novellis P, Bottoni E, Voulaz E, Cariboni U, Testori A, Bertolaccini L, et al. Robotic surgery, video-assisted thoracic surgery, and open surgery for early stage lung cancer: comparison of costs and outcomes at a single institute. J Thorac Dis. 2018;10: $790-8$.

16. Veluswamy RR, Whittaker Brown SA, Mhango G, Sigel K, Nicastri DG, Smith CB, et al. Comparative effectiveness of robotic-assisted surgery for resectable lung cancer in older patients. Chest. 2020;157:1313-21 Single center study comparing robotic assisted surgery, video-assisted thoracoscopic surgery and open surgery for lung resection. In a matched study cohort of $\mathbf{2 . 7 6 6}$ patients the perioperative outcomes and costs were analyzed.

17. Darr C, Cheufou D, Weinreich G, Hachenberg T, Aigner C, Kampe S. Robotic thoracic surgery results in shorter hospital stay and lower postoperative pain compared to open thoracotomy: a matched pairs analysis. Surg Endosc. 2017;31:4126-30.

18. Guo F, Ma D, Li S. Compare the prognosis of Da Vinci robotassisted thoracic surgery (RATS) with video-assisted thoracic surgery (VATS) for non-small cell lung cancer: a meta-analysis. Medicine (Baltimore). 2019;98:e17089. https://doi.org/10.1097/ MD.0000000000017089.

19. Heller JA, Bhora FY, Heller BJ, Cohen E. Robotic-assisted thoracoscopic lung surgery: anesthetic impact and perioperative experience. Minerva Anestesiol. 2018;84:108-14. https://doi.org/ 10.23736/S0375-9393.17.12168-1.

20. Kozian A, Schilling T, Strang C, Hachenberg T. Anesthetic considerations in patients with previous thoracic surgery. Curr Opin Anaesthesiol. 2006;19:26-33.

21. Matheos T, Ram L, Cynelli R. Preoperative Evaluation for Thoracic Surgery. Thorac Surg Clin. 2020;30(3):241-7. https://doi.org/10. 1016/j.thorsurg.2020.04.003.

22. Kim M, Eagle K. Cardiac risk assessment in noncardic thoracic surgery. Semin Thorac Cardiovasc Surg. 2001;13:2. https://doi. org/10.1053/stcs.2001.24618. 
23. Gelzinis T, Assaad S, Perrino A. Right ventricular function during and after thoracic surgery. Curr Opin Anaesthesiol. 2020 Feb;33(1): 27-36. https://doi.org/10.1097/ACO.0000000000000809.

24. Brunelli A, Charloux A, Bolliger CT, Rocco G, Sculier JP, Varela G, et al. European Society of Thoracic Surgeons Joint Task Force on Fitness For Radical Therapy. The European Respiratory Society and European Society of Thoracic Surgeons clinical guidelines for evaluating fitness for radical treatment (surgery and chemoradiotherapy) in patients with lung cancer. Eur J Cardiothorac Surg. 2009;36:181-4.

25. Bernstein W, Deshpande S. Preoperative evaluation for thoracic surgery. Semin Cardiothorac Vasc Anesth. 2008 Jun;12(2):10921. https://doi.org/10.1177/1089253208319868.

26. Bernstein W. Pulmonary function testing. Curr Opin Anaesthesiol. 2012;25:11-6. https://doi.org/10.1097/ACO.0b013e32834e7ad2.

27. Vannucci A, Cavallone LF. Bedside predictors of difficult intubation: a systematic review. Minerva Anestesiol. 2016;82:69-83.

28. P. Slinger (ed.), Principles and practice of anesthesia for thoracic surgery, https://doi.org/10.1007/978-3-030-00859-8 2

29. Selvi O, Kahraman T, Senturk O, Tulgar S, Serifsoy E, Ozer Z. Evaluation of the reliability of preoperative descriptive airway assessment tests in prediction of the Cormack-Lehane score: a prospective randomized clinical study. J Clin Anesth. 2017;36:21-6. https://doi.org/10.1016/j.jclinane.2016.08.006 Epub 2016 Oct 31.

30. Bayes J, Slater EM, Hedberg PS, Lawson D. Obstruction of a double-lumen endotracheal tube by a saber-sheath trachea. Anesth Analg. 1994 Jul;79(1):186-8. https://doi.org/10.1213/00000539$199407000-00036$.

31. Lahkar B, Dutta K. Benzodiazepine premedication in general anaesthesia: a clinical comparative study. International Journal of Clinical Trials. 2019;6:2. https://doi.org/10.18203/2349-3259. ijct20190983.

32. van der Ploeg APT, Ayez N, Akkersdijk GP, van Rossem CC, de Rooij PD. Postoperative pain after lobectomy: robot-assisted, video-assisted and open thoracic surgery. J Robot Surg. 2020;14: 131-6.

33. Piccioni F, Droghetti A, Bertani A, Coccia C, Corcione A, Corsico $\mathrm{AG}$, et al. Recommendations from the Italian intersociety consensus on Perioperative Anesthesia Care in Thoracic surgery (PACTS) part 1: preadmission and preoperative care. Perioper Med (Lond). 2020;9:37. Published online 2020 Dec 1. https://doi.org/10.1186/ s13741-020-00168-y.

34. Kawagoe I, Hayashida M, Satoh D, Kochiyama T, Fukuda M, Kishii J. Postoperative analgesia in patients undergoing robotassisted thoracic surgery: a comparison between thoracic epidural analgesia and intercostal nerve block combined with intravenous patient-controlled analgesia. Ann Palliat Med. 2021;10:1985-93.

35. Takenaka T, Shoji F, Tagawa T, Kinoshita F, Haratake N, Edagawa $\mathrm{M}$, et al. Does short-term cessation of smoking before lung resections reduce the risk of complications? J Thorac Dis. 2020;12: 7127-34 This article highlights the persistent risk of postoperative pulmonary complications in patients following smoking cessation for 4 weeks. Multi-center retrospective cohort analysis in 753 patients undergoing lung resection for malignant disease.

36. Ferreira V, Lawson C, Ekmekjian T, Carli F, Scheede-Bergdahl C, Chevalier S. Effects of preoperative nutrition and multimodal prehabilitation on functional capacity and postoperative complications in surgical lung cancer patients: a systematic review. Support Care Cancer. 2021. https://doi.org/10.1007/s00520-021-06161-5.

37. Kapur A, Kapur V. Robotic surgery: anaesthesiologist's contemplation. Malays J Med Sci. 2020;27:143-9.

38. Hermsen ED, Hinze T, Sayles H, Sholtz L, Rupp ME. Incidence of surgical site infection associated with robotic surgery. Infect Control Hosp Epidemiol. 2010;31:822-7.

39. Chang SH, Krupnick AS. Perioperative antibiotics in thoracic surgery. Thorac Surg Clin. 2012;22:35-45.
40. Meggiolaro KM, Wulf H, Feldmann C, Wiesmann T, Schubert AK, Risse J. Airway management for lung separation in thoracic surgery: an update. Anaesthesist. 2018;67:555-67.

41. Bernasconi F, Piccioni F. One-lung ventilation for thoracic surgery: current perspectives. Tumori. 2017;103:495-503.

42. Kreft T, Hachenberg T. Use of bronchial blockers for lung isolation. Anästhesiol Intensivmed Notfallmed Schmerzther. 2018;53(03): 198-210. https://doi.org/10.1055/s-0043-114677.

43. Lu Y, Dai W, Zong Z, Xiao Y, Wu D, Liu X, et al. Bronchial blocker versus left double-lumen endotracheal tube for one-lung ventilation in right video-assisted thoracoscopic surgery. J Cardiothorac Vasc Anesth. 2018 Feb;32(1):297-301. https://doi. org/10.1053/j.jvca.2017.07.026 Epub 2017 Jul 27.

44. Piccioni F, Droghetti A, Bertani A, Coccia C, Corcione A, Corsico $\mathrm{AG}$, et al. Recommendations from the Italian intersociety consensus on Perioperative Anesthesa Care in Thoracic surgery (PACTS) part 2: intraoperative and postoperative care. Perioper Med (Lond). 2020;9:31. Published online 2020 Oct 23. https://doi.org/10.1186/ s13741-020-00159-z.

45.• Casiraghi M, Galetta D, Borri A, Tessitore A, Romano R, Diotti C, et al. Ten years' experience in robotic-assisted thoracic surgery for early stage lung cancer. Thorac Cardiovasc Surg. 2019;67:564-72

Single center short- and long-term analysis of 339 patients undergoing robotic-assisted thoracoscopic lung resection between 2006 and 2016. The conversion rate due to technical issues was $4.4 \%$. Bleeding complications occurred only in $0.9 \%$ of cases.

46. Campos J, Ueda K. Update on anesthetic complications of robotic thoracic surgery. Minerva Anestesiol. 2014;80:83-8.

47. Horn EP, Klar E, Höcker J, Bräuer A, Bein B, Wulf H, et al. Prevention of perioperative hypothermia: implementation of the S3 guideline. Chirurg. 2017;88:422-8.

48. Torossian A, Bräuer A, Höcker J, Bein B, Wulf H, Horn EP. Preventing inadvertent perioperative hypothermia. Dtsch Arztebl Int. 2015;112:166-72.

49. Torossian A, Becke K, Bein B, Bräuer A, Gantert D, Greif R, Höcker J, Horn EP, Kimberger O, Klar E, Nuhn P, Ruchholtz S, Schwappach D, Welk I, Wulf H. S3-guideline prevention of perioperative hypothermia. 2019. Arbeitsgemeinschaft der Wissenschaftlichen Medizinischen Fachgesellschaften (AWMF) e.V. 2015. https://www.awmf.org/uploads/tx_szleitlinien/0010181_S3_Vermeidung perioperativer_Hypothermie 2019-08.pdf. Accessed 26.04.2021

50. Ahmed AB, Koster A, Lance M, Faraoni D, ESA VTE Guidelines Task Force. European guidelines on perioperative venous thromboembolism prophylaxis: cardiovascular and thoracic surgery. Eur J Anaesthesiol. 2018;35:84-9.

51. Encke A, Haas S, Kopp, I. S3 guideline prophylaxis of venous thrombembolism. In: Arbeitsgemeinschaft der Wissenschaftlichen Medizinischen Fachgesellschaften (AWMF) e.V. 2015. https:// www.awmf.org/uploads/tx szleitlinien/003-0011 S3 VTEProphylaxe_2015-10-abgelaufen_01.pdf. Accessed 26.04.2021.

52. Agzarian J, Linkins LA, Schneider L, Hanna WC, Finley CJ, Schieman C, et al. Practice patterns in venous thromboembolism (VTE) prophylaxis in thoracic surgery: a comprehensive Canadian Delphi survey. J Thorac Dis. 2017;9:80-7.

53. Hachey KJ, Sterbling H, Choi DS, Pinjic E, Hewes PD, Munoz J, et al. Prevention of postoperative venous thromboembolism in thoracic surgical patients: implementation and evaluation of a Caprini risk assessment protocol. J Am Coll Surg. 2016;222:1019-27.

54. Jonsson M, Hurtig-Wennlöf A, Ahlsson A, Vidlund M, Cao Y, Westerdahl E. In-hospital physiotherapy improves physical activity level after lung cancer surgery: a randomized controlled trial. Physiotherapy. 2019;105:434-41.

55. Castelino T, Fiore JF Jr, Niculiseanu P, Landry T, Augustin B, Feldman LS. The effect of early mobilization protocols on 
postoperative outcomes following abdominal and thoracic surgery: a systematic review. Surgery. 2016;159:991-1003.

56. Kendall F, Abreu P, Pinho P, Oliveira J, Bastos P. The role of physiotherapy in patients undergoing pulmonary surgery for lung cancer. A literature review. Rev Port Pneumol. 2006;2017(23): 343-51.

57. Agostini P, Lugg ST, Adams K, Smith T, Kalkat M, Rajesh PB, et al. Video-assisted thoracoscopic lobectomy: which patients require postoperative physiotherapy? Physiotherapy. 2020;106:8793 Study addresses the selection of patients for postoperative physiotherapy. Prospective single-center cohort analysis in $\mathbf{2 8 5}$ patients undergoing video-assisted thoracoscopic surgery. Screening of COPD, BMI, preoperative mobility and age will allow early identification of patients who may benefit most from postoperative physiotherapy and preoperative optimization.

58. Agostini P, Naidu B, Cieslik H, Steyn R, Rajesh PB, Bishay E, et al. Effectiveness of incentive spirometry in patients following thoracotomy and lung resection including those at high risk for developing pulmonary complications. Thorax. 2013;68:580-5.

59. Malik PRA, Fahim C, Vernon J, Thomas P, Schieman C, Finley CJ, et al. Incentive spirometry after lung resection: a randomized controlled trial. Ann Thorac Surg. 2018;106:340-5.

60. Brunelli A, Beretta E, Cassivi SD, Cerfolio RJ, Detterbeck F, Kiefer $\mathrm{T}$, et al. Consensus definitions to promote an evidence-based approach to management of the pleural space. A collaborative proposal by ESTS, AATS, STS, and GTSC. Eur J Cardiothorac Surg. 2011;40:291-7.

61. Linder A, Ertner C, Steger V, Messerschmidt A, Merk J, Cregan I, et al. Postoperative chest tube management: snapshot of German diversity. Interact Cardiovasc Thorac Surg. 2012;15:622-6.
62.•• Gao S, Zhang Z, Aragón J, Brunelli A, Cassivi S, Chai Y, et al. The Society for Translational Medicine: clinical practice guidelines for the postoperative management of chest tube for patients undergoing lobectomy. J Thorac Dis. 2017;9:3255-64 The duration of chest tubes following lung surgery has been identified as important risk factor for postoperative pulmonary complications. This international consensus article addresses the highly controversial topic of postoperative chest tube management. Evidencebased recommendation are made regarding the key-issues of chest tube operation and removal.

63. Pompili C, Detterbeck F, Papagiannopoulos K, Sihoe A, Vachlas $\mathrm{K}$, Maxfield MW, et al. Multicenter international randomized comparison of objective and subjective outcomes between electronic and traditional chest drainage systems. Ann Thorac Surg. 2014;98:490-6.

64. Xie HY, Xu K, Tang JX, Bian W, Ma HT, Zhao J, et al. A prospective randomized, controlled trial deems a drainage of $300 \mathrm{ml} /$ day safe before removal of the last chest drain after video-assisted thoracoscopic surgery lobectomy. Interact Cardiovasc Thorac Surg. 2015;21:200-5.

65. Olgac G, Cosgun T, Vayvada M, Ozdemir A, Kutlu CA. Low protein content of drainage fluid is a good predictor for earlier chest tube removal after lobectomy. Interact Cardiovasc Thorac Surg. 2014;19:650-5.

Publisher's Note Springer Nature remains neutral with regard to jurisdictional claims in published maps and institutional affiliations. 